\title{
Hydrothermal Green Synthesis of Silver Nanoparticles using Azadirachta indica A. Juss. Fruit Juice for Potential Antibacterial Activity
}

\author{
K. Ramar, A. Jafar Ahamed* \\ Post Graduate and Research Department of Chemistry, Jamal Mohamed College (Autonomous), Tiruchirappalli - 620 020, Tamilnadu, India.
}

\section{ART ICLE DETAILS}

Article history:

Received 30 August 2018

Accepted 16 September 2018

Available online 28 October 2018

\section{Keywords:}

Hydrothermal

Green Synthesis

Azadirachta indica A. Juss.

Ag NPs

\begin{abstract}
A B S T R A C T
This study employed a green, eco-friendly and convenient hydrothermal method for the synthesis of stable silver nanoparticles (Ag NPs) using neem (Azadirachta indica A Juss) fruit extract, which also acts as a reducing and capping agents. Since neem fruits has been found to have various medicinal applications, this fruit has been chosen in this paper to obtain Ag NPs. The Ag NPs were characterized by PXRD, UV-Vis diffuse reflectance spectra (DRS), FTIR, FESEM-EDAX, and HRTEM analysis. UV-Vis DRS spectra studies provided sufficient evidences for the formation of Ag NPs. The major role of functional groups present in the synthesis and stabilization of the NPs was obtained from FTIR studies. The PXRD and HRTEM investigations clearly demonstrated the crystalline nature of the NPs. From the HRTEM images, the Ag NPs were found to be spherical and of nearly uniform size with an average size of $13 \mathrm{~nm}$. Further, Ag NPs were subjected to the agar disc diffusion antimicrobial assay (Mueller-Hinton Agar testing) against Gram-negative Escherichia coli (E. coli) and Gram-positive Staphylococcus aureus (S. aureus) bacteria. The test results showed the potent antibacterial activity of NPs for Gram-positive bacteria is higher than that the Gram- negative bacteria.
\end{abstract}

\section{Introduction}

Nanomaterials are a new class of materials with ultrafine particles having a size in the range of $1-100 \mathrm{~nm}$. Their small size determine all the properties (chemical, physical and biological) and changes in fundamental behaviors of both individually atoms/molecules and their corresponding bulk forms [1]. Colloidal noble metal nanoparticles like silver, gold and platinum are considered for be the important materials because they are widely used for human needs including soaps, shampoos, detergents, cosmetic products and industrial used to different colors depending on the size, shape, and the tendency of aggregation [2]. Among noble metal, Ag NPs have attained a special focus because they are widely used for many application such as optical device [3], catalysis [4], electrochemical analysis [5], optical device [6], photonics [7], electronics [8], information storage [9], biosensing [10], has widened its research scope."

Generally, Ag NPs can be synthesized by a number of approaches, i.e., physical, chemical and biological methods including electrochemical [11], sonochemical [12], thermal decomposition [13], microwave assisted [14], solvothermal [15], photochemical reduction [16], phytosynthesis [17], and chemical reduction [18]. The above mentioned methods cannot avoid the use of toxic chemicals and solvents and also generate hazardous toxic wastes. Therefore, there is a growing need to develop ecofriendly processes to avoid the use of toxic and hazardous chemicals in their synthesis which is also known as "biological synthesis". Biological methods of nanoparticle synthesis using bacteria [19], fungi [20], and plants or plant extracts [21] have been suggested as possible eco-friendly alternatives to chemical and physical methods. Using plants for nanoparticle synthesis can be advantageous over other biological processes such as microbial route, because it requirement of specialized facilities, long time consumption, and biohazards production.

In current trend of research work, the researchers use natural plant materials based on their eco-friendly and inexpensive nature for the synthesis of metal nanoparticles. All parts of a plant including leaves, fruits, roots, seeds, and stems can be used for the synthesis of metal nanoparticles. On the other hand, plant materials contain chemical compounds like amino acids, proteins, polysaccharides, alkaloids, flavonoids and phenolic compounds etc., which act as reducing agents as well as stabilizing agents. Recently, green synthesis of Ag NPs have been reported using various herbs such as Alfalfa [22], broths of Geranium [23], Neem [24], and Emblica officinalis fruit [25], as well as Aloe vera leaves [26], extracts of Chlorella vulgaris [27], Coffee and Tea [28], Camellia sinensis [29], Azadirachta indica leaf [30] have been used to prepare Ag NPs.

According to Nair and Henry, Neem (Azadirachta indica A. Juss), a meliaceae family tree, is a hardy evergreen tree commonly found in all parts of India [31]. The Azadirachta indica A. Juss. plant contains for triterpenoids, steroid, flavonoids, nimbin, salannin and phenolic compounds [32, 33]. And also the plant leaf extracts higher the properties of NPs like antibacterial, antioxidant activity etc., [34,35]. In this present work, we have synthesized Ag NPs using neem fruit extract as a reducing and stabilizing agent by green method and their physicochemical characteristics was evaluated. In order to verify the antimicrobial potential of obtained NPs was performed against Gram-negative E. coli and Gram-positive $S$. aureus.

\section{Experimental Methods}

\subsection{Materials}

Fruits of Azadirachta indica A. Juss. were collected from Jamal Mohamed College campus and authenticated by Dr. S. Jayaraman, Director of Plant and Anatomy Research Centre, Chennai. (Reg.No. PARC/2016/3239). Silver nitrate $\left(\mathrm{AgNO}_{3}\right)$ (99.99\%) was procured from Sigma Aldrich, Mumbai. Terephthalic acid (TA) and sodium hydroxide $(\mathrm{NaOH})$ used in the present study were procured from SRL fine Chemicals Ltd. Mumbai, India. Deionized water has been used as the solvent throughout this experiment.

\subsection{Preparation of Fruits Extract}

The fruits of neem were initially washed several times with deionized water and dried for $2 \mathrm{~h}$ in the presence of sunlight. Then $50 \mathrm{~g}$ of fruits were taken in a $250 \mathrm{~mL}$ round bottom flask along with $100 \mathrm{~mL}$ of deionized water and kept under magnetic stirring for 24 hours at room temperature. Aqueous fruit solution obtained was then filtered to separate the extract from fruits and stored in the refrigerator for further use. 


\subsection{Hydrothermal Preparation of Ag NPs}

In a typical synthesis, $10 \mathrm{~mL}$ of aqueous fruit extract of neem was added to $90 \mathrm{~mL}$ of $1 \mathrm{mM}$ aqueous $\mathrm{AgNO}_{3}$ solution. The mixture is then poured into a sealed teflon-lined autoclave of $100 \mathrm{~mL}$ capacity, which was heated and maintained at a temperature of $150{ }^{\circ} \mathrm{C}$ for reaction time of $3 \mathrm{~h}$ and then gradually cooled to room temperature. The Ag NPs were collected by centrifugation and washed with water for several times and then dried in a vacuum oven at $50{ }^{\circ} \mathrm{C}$ and used for further characterization and studies.

\subsection{Instrumentation}

UV-Vis diffuse reflectance spectra (UV-Vis DRS) Jasco V-770 was used for studying the spectral response of Ag NPs. Fourier-transform infrared spectroscopy (FTIR) results were acquired from Jasco 6300 spectrometer (ATR mode) in the range of $400-4000 \mathrm{~cm}^{-1}$. Field emission scanning electron microscopy (FESEM) images were recorded using an Ultra 55 Carl Zeiss instrument with an operating voltage of $10 \mathrm{kV}$. Samples for the FESEM analysis were mounted on a stub using a conductive carbon tape. High resolution transmission electron microscopy (HRTEM) and selected area electron diffraction (SAED) images were recorded using an FEI Technai G220 STEM instrument operated at an acceleration voltage of 200 $\mathrm{kV}$. Powder X-ray Diffraction (PXRD) was carried out using X-ray diffractometer - CuK $\alpha$ radiation (Rigaku, Miniflex-600, Japan). The photoluminescence (PL) emission and excitation spectra were recorded on a Horiba Jobin Yvon model Fluoromax-4 Spectrophotometer.

\subsection{Antibacterial Activity}

The antibacterial activity of the Ag NPs was determined by the diffusion method against Gram-negative $E$. coli Gram-positive $S$. aureus on Mueller Hinton Agar, according to the Clinical and Laboratory Standards Institute (CLSI) [36]. The media plates (MHA) were streaked with bacteria 2-3 times by rotating the plate at $60^{\circ}$ angles for each streak to ensure the homogeneous distribution of the inoculums. After inoculation, discs $(6$ mm Hi-Media) loaded with $75 \mu \mathrm{L} / \mathrm{mL}$, of the test sample was placed on the bacteria-seeded well plates using micropipettes. The plates were then incubated at $37{ }^{\circ} \mathrm{C}$ for $24 \mathrm{~h}$. The inhibition zone around the well was measured and recorded. Amoxicillin (Hi-Media) was used as the positive controls against $S$. aureus and $E$. coli bacteria respectively to compare the efficacy of the test samples.

\section{Results and Discussion}

\subsection{Powder X-Ray Diffraction (PXRD)}

The powder X-ray diffraction (PXRD) patterns of the synthesized Ag NPs were used to determine their crystalline phase and structure. The PXRD pattern (Fig. 1) showed four major peaks at $2 \theta 37.97,44.12,64.34$, and $77.39^{\circ}$ corresponding to the indices (111), (200), (220) and (311) are in good agreement with JCPDS 04-0783 which confirmed that the synthesized Ag NPs are crystalline nature with the fcc crystal structure [37]. The following Debye-Scherrer's equation was used to calculate the size of Ag NPs from XRD data at $37.97^{\circ}$.

$$
\mathrm{D}=(0.9 \lambda) / \beta \cos \theta
$$

where $\lambda$ is the wavelength of X-ray used $(0.15418 \mathrm{~nm}$ in the present case), $\beta$ is the full width in radiation at half-maximum of the peak, and $\theta$ is the Bragg angle of X-ray diffraction peak. The PXRD plane (111) was chosen to calculate the crystallite size for Ag NPs and the average particle size was found to be around $28 \mathrm{~nm}$.

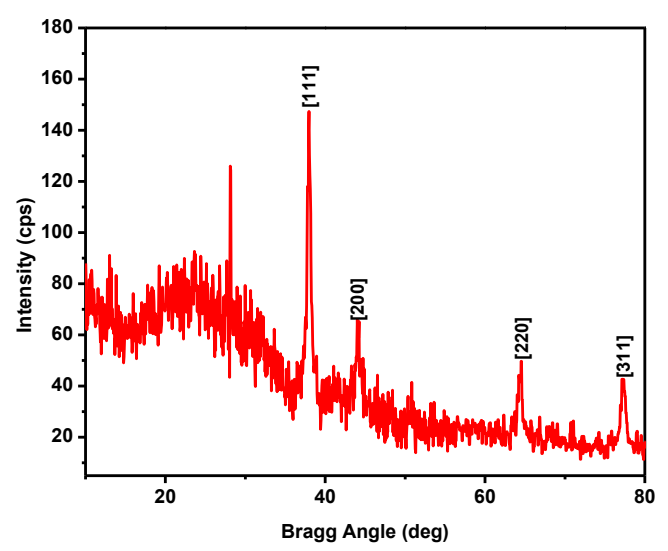

Fig. 1 XRD pattern of synthesized Ag NPs

https://doi.org/10.30799/jnst.160.18040515

\subsection{Fourier Transform Infrared Spectroscopy (FTIR)}

FTIR analysis was conducted to identify the possible functional groups or moieties in the plant extract responsible for the reduction of $\mathrm{Ag}$ ions and stabilization of the Ag NPs as shown in Fig. 2. Two major FTIR bands were found in the spectra of Ag NPs one around $3350 \mathrm{~cm}^{-1}$ and another at $1635 \mathrm{~cm}^{-1}$ which correspond to $\mathrm{O}-\mathrm{H}$ and $\mathrm{N}-\mathrm{H}$ bond stretching and bending respectively [38, 39]. The functional groups like primary and secondary amines, triterpenoids, steroid, flavonoids, alkanes, alcohols, esters present in the leaves extract might be responsible for the reduction of Ag NPs from $\mathrm{AgNO}_{3}$ solution [40].

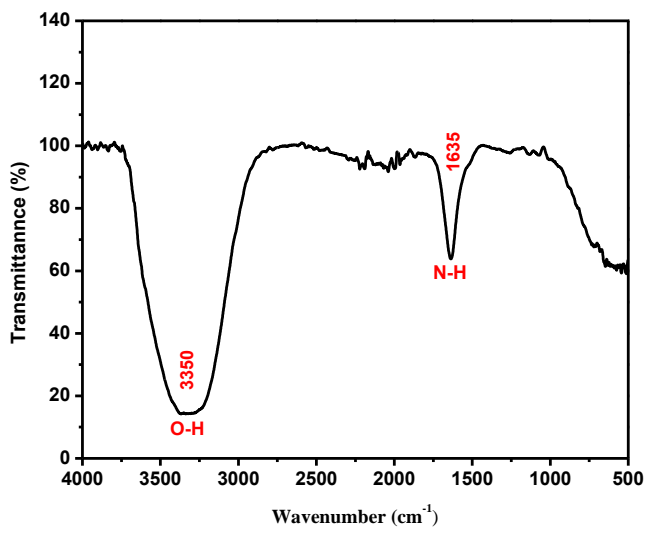

Fig. 2 FTIR spectrum of synthesized Ag NPs

\subsection{Field Emission Scanning Electron Microscopy - Energy Dispersive X-Rays} (FESEM-EDAX)

Fig. 3a-c shows the FESEM image representing the surface morphology of synthesized Ag NPs. FESEM results show that Ag NPs are obtained as smaller spherical shape NPs with the particle size ranging from $12 \mathrm{~nm}$ to $33 \mathrm{~nm}$. The EDAX pattern (Fig. 3d) showed the chemical compositions of NPs to contain silver (78.64 weights\%), oxygen (4.80 weight\%), carbon (11.05 weight $\%)$ and a weak nitrogen ( 5.51 weight $\%$ ) peak. The oxygen, carbon and nitrogen signal might be due to the presence of biomolecules bound to the surface of the synthesized NPs.

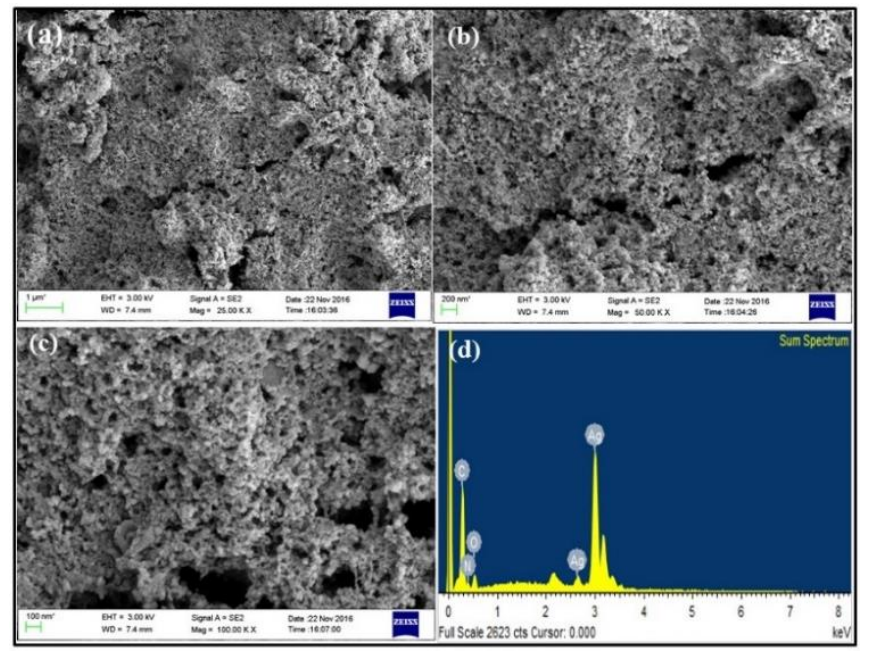

Fig. 3 (a-c) FESEM images of synthesized Ag NPs at different magnifications and (d) EDAX spectrum of synthesized Ag NPs

\subsection{High Resolution - Transmission Electron Microscopy (HR-TEM)}

The surface morphology and structural size of synthesized Ag NPs using Azadirachta indica A. Juss. fruit extract were analyzed using HRTEM images as shown in Fig. 4(a-e). It can be clearly seen from the image that the Ag NPs were found to be spherical in shape with an average size of 13 $\mathrm{nm}$. The Fig. 4(e) lattice fringe width of $0.326 \mathrm{~nm}$ corresponds to (111) facets of the fcc crystal structure. Selected Area Electron Diffraction (SAED) pattern (Fig. 4f) showed ring-like pattern indicating the crystalline natural of Ag NPs.

\subsection{UV-Visible Spectroscopy}

Optical properties of Ag NPs were characterized using UV-Vis DRS spectrophotometer as shown in Fig. 5. Ag NPs formation was confirmed by the absorption peak at $K_{\max }=431 \mathrm{~nm}$. This results obtained in the present study are in good agreement with earlier reports. The optical band gap 
energy of the synthesized Ag NPs has been calculated using formula by following earlier reports. From UV-Vis DRS spectrum data the calculated direct band gap is $1.9 \mathrm{eV}$ as shown in inset Fig. 5 .

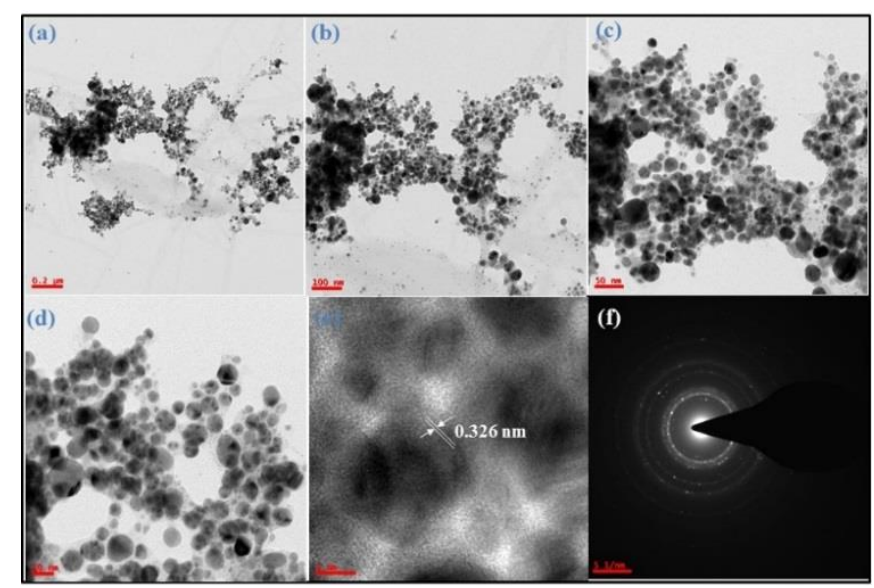

Fig. 4 HRTEM micrographs (a-c), lattice fringes (d, e) and SAED pattern (f) of synthesized Ag NPs

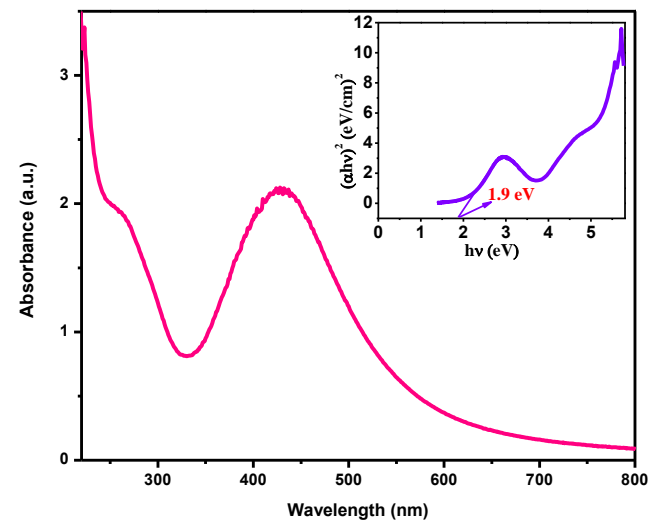

Fig. 5 UV-Visible DRS spectra of synthesized Ag NPs and inset the plot of transformed $(\alpha \mathrm{h} v) 1 / 2$ versus the photon energy (hv)

\subsection{Thermal Studies}

To confirm that the plant extracts were conjugated to Ag NPs, TGA analysis on Ag NPs has been done as shown in Fig. 6. An initial weight loss $(-7 \%)$ of Ag NPs under $226^{\circ} \mathrm{C}$ is likely to be removal of surface moisture and evaporation of adsorbed water [41]. The second stage at about 266 to $313^{\circ} \mathrm{C}$, there was a loss in weight of approximately $(-12 \%)$ corresponding to the removal of chemisorbed water and the breakdown of the organic skeleton, respectively [35]. The organic skeleton of neem fruit extract decomposes completely at temperature $391{ }^{\circ} \mathrm{C}$, which is indicated by a weight loss of $15 \%$ and we did not observe any weight loss at higher temperature beyond $391{ }^{\circ} \mathrm{C}$ indicating that the remaining residual weight of Ag NPs as $66 \%$ [2].

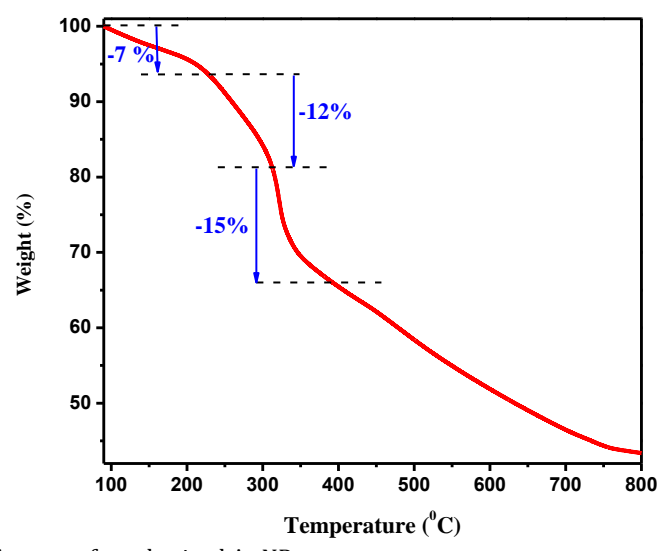

Fig. 6 TGA curve of synthesized Ag NPs

\subsection{Zeta Sizer and Zeta Potential}

The preliminary confirmation for the size distribution and polydispersity index of particles in a colloidal suspension of Ag NPs was carried out by dynamic light scattering (DLS) spectroscopy. Fig. 7a shows https://doi.org/10.30799/jnst.160.18040515 the result of DLS plot obtained, according to which average particle diameter is $34.9 \mathrm{~nm}$ and PDI was found to be 3.222 [42].

Zeta potential has been suggested to play an important role in the stability of colloidal solution of Ag NPs. The Ag NPs gave a peak at-27.1mV, in which a negative value indicates a highly stable colloidal solution (Fig. $7 \mathrm{~b})$. The negative zeta potential values implies that, the nanoparticle was capped by the fruit extract [43].
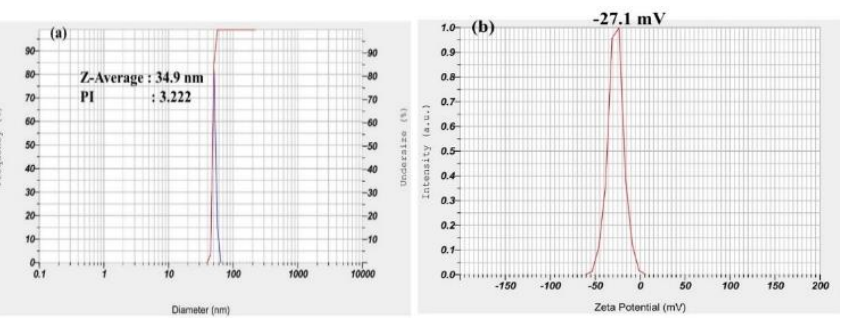

Fig. 7 (a) Zeta sizer and (b) Zeta potential of synthesized Ag NPs

\subsection{Antimicrobial Activities}

Ag NPs are of specific interest as antibacterial agents, as they can be prepared with very high surface areas and crystalline morphologies with a high number of edges and corners, and other potentially reactive sites. The antibacterial effect of Ag NPs was evaluated against both Gramnegative and Gram-positive bacteria. Table 1 indicates that diameter of the zone of inhibition that could be observed for both Gram-negative E. coli and Gram-positive $S$. aureus bacteria, which changes depending upon the concentration of Ag NPs. As concentration increases from 30 to $50 \mu \mathrm{g}$ the inhibition zone diameter also increases. Fig. 8 shows the images of the zone of inhibition. The antibacterial activity of NPs for Gram- positive bacteria is higher than that for Gram-negative bacteria which may be due to the structural differences in the cell walls of E. coli and S. aureus bacteria. Interestingly, an $E$. coli bacteria cell wall is composed of a thin lipoprotein layer and a single layer of peptidoglycan. The peptidoglycan is placed within the lipids and polysaccharides exhibiting a negative charge, which serves as a permeability barrier to the Ag NPs having a positive charge.

To understand the surface charge interactions of Ag NPs, the zeta potential was determined. The zeta potential value of $-27.1 \mathrm{mV}$ (Fig. 7b) showed that the NPs is positively charged. Generally, stable colloidal suspension has zeta potential values higher than $+30 \mathrm{mV}$ or lower than $-30 \mathrm{mV}$. A permeability barrier interaction is possible between the NPs and $E$. coli bacteria surfaces thus resulting in less adsorption of bacterial cell on the surface of Ag NPs. On the other hand, the $S$. aureus bacteria cell wall is composed of a thick and multi peptidoglycan layer comprising of linear polysaccharide chains cross-linked by short peptides to form a three-dimensional rigid structure. This rigid layer, in turn, restricts the attachment or penetration of the Ag NPs to the cell wall. The electrostatic interaction of Ag NPs to the bacterial surface is very less. These repulsions are attributed to the positive potentials on NPs and bacterial surfaces, which not hinder the diffusion of Ag NPs into the cell. Thus resulting in good adsorption of the bacterial cells on the surface of Ag NPs [44].

Table 1 The zone of inhibition (ZOI) for both E. coli and S. aureus bacteria against different concentrations of synthesized Ag NPs

\begin{tabular}{lll}
\hline $\begin{array}{l}\text { Concentration of sample } \\
(\mu \mathrm{g})\end{array}$ & Zone of inhibition $(\mathrm{mm})$ \\
\cline { 2 - 3 } & S. aureus & E. coli \\
\hline 30 & 13 & 13 \\
40 & 14 & 14 \\
50 & 19 & 15 \\
Amoxicillin & 15 & 13 \\
\hline
\end{tabular}

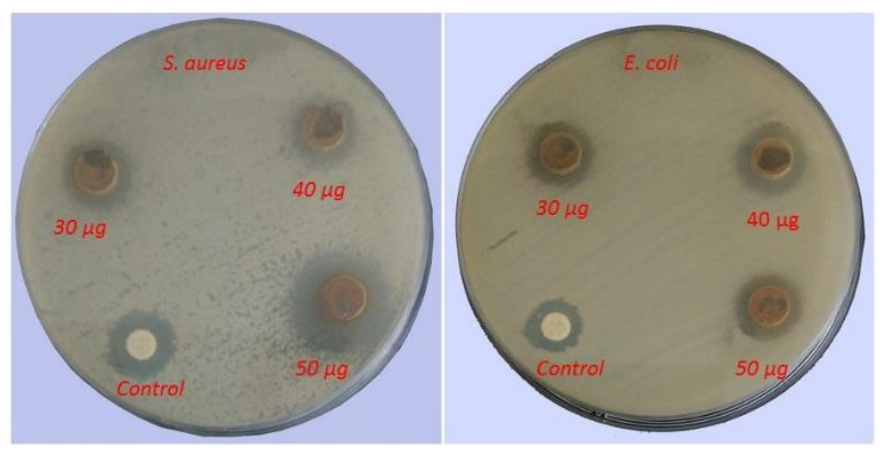

Fig. 8 The microbial growth inhibitions by synthesized Ag NPs against (a) S. aureus and (b) E. coli at different dose concentrations 
In the present study, the antibacterial effects of the Ag NPs were mainly due to the combination of various factors such as ROS and the release of $\mathrm{Ag}^{+}$. The generation of reactive oxygen species like $\mathrm{OH}^{\bullet}$ and $\mathrm{O}^{2-}$ is explained below. Since Ag with defects can be activated by both UV and visible light, electron-hole pairs $\left(e-h^{+}\right)$can be created. The holes react with $\mathrm{H}_{2} \mathrm{O}$ molecules on the $\mathrm{Ag}$ surface to form $\mathrm{OH}^{-}$and $\mathrm{H}^{+}$. Dissolved oxygen molecules are transformed to superoxide radical anions $\left({ }^{\circ} \mathrm{O}^{2-}\right)$, which in turn react with $\mathrm{H}^{+}$to generate $\left(\mathrm{HO}_{2}{ }^{*}\right)$ radicals, which upon subsequent collision with electrons produce hydrogen peroxide anions $\left(\mathrm{HO}_{2}^{-}\right)$. Then they react with hydrogen ions to form molecules of $\mathrm{OH}^{-}$and $\mathrm{H}^{+}$. These reactive radicals and intermediate species react with bacteria, and then can penetrate the cell membrane and kill the bacteria.

The above mechanism of the light-induced generation of ROS can be given in equation form as below:

$$
\begin{aligned}
& \mathrm{Ag}+\mathrm{hv} \rightarrow \mathrm{e}^{-}+\mathrm{h}^{+} \\
& \mathrm{h}^{+}+\mathrm{H}_{2} \mathrm{O} \rightarrow \cdot{ }^{\circ} \mathrm{OH}+\mathrm{H}^{+} \\
& \mathrm{e}^{-}+\mathrm{O}_{2} \rightarrow \cdot \mathrm{O}_{2}^{-} \\
& \mathrm{O}_{2}^{-}+\mathrm{H}^{+} \rightarrow \mathrm{HO}_{2}^{\bullet} \\
& \mathrm{HO}_{2}^{\bullet}+\mathrm{H}^{+} \rightarrow \mathrm{HO}^{\bullet}+\mathrm{OH}^{-}
\end{aligned}
$$

Bacteria + Reactive oxygenated radical $\rightarrow$ Cell death

In ROS studies, there are two common pathways for the cell death of cellular components: through a direct oxidation reaction by generated holes, and through oxidative radicals. The formation of hydroxyl radicals $\left(\mathrm{OH}^{*}\right)$ by the Ag NPs was further measured by the emission of photoluminescence (PL) technique using terephthalic acid (TA) as the probing molecule. TA reacts with the $\mathrm{OH}^{\bullet}$ radical resulting a highly fluorescent product of 2-hydroxyterephthalate that has the timedependent fluorescence emission peak at $461 \mathrm{~nm}$ with an excitation wavelength of $350 \mathrm{~nm}$, as shown in Fig. 9. With increases in PL intensity at around $461 \mathrm{~nm}$ with irradiation time is caused by chemical reactions of terephthalic acid with $\mathrm{OH} \cdot$ formed at the Ag NPs /water interface. Using Ag NPs the generation of $\mathrm{OH}^{*}$ radicals as well as antibacterial effects is improved.

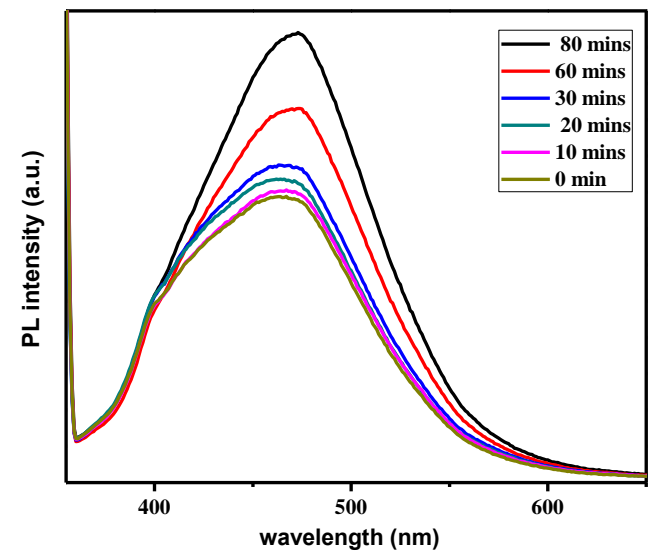

Fig. 9 Fluorescence spectrum of $\mathrm{OH} \cdot$ radical trapping by terephthalic acid

\section{Conclusion}

Ag NPs were successfully synthesized by a hydrothermal green method using neem fruit extract as a reducing and stablizing angens. The formation of Ag NPs was confirmed by the UV-Visible DRS absorption spectra, which showed a peaks at $431 \mathrm{~nm}$. The PXRD result confirmed that the Ag NPs possessed crystalline nature with the fcc crystal structure. The HRTEM images showed that the Ag NPs were spherical in shape with an average size of $13 \mathrm{~nm}$. The studied Ag NPs were an excellent antibacterial agents which was confirmed increasing zone of inhibition against Grampositive bacteria high activity compare to Gram-negative bacteria.

\section{Acknowledgement}

The financial support from UGC Networking Resource Centre, School of Chemistry, University of Hyderabad is acknowledged. The authors gratefully thank Prof. K. Muralidharan from University of Hyderabad and KIRND Institute of Research and development, Trichy for providing necessary facilities for the present study.

\section{References}

[1] B. Kumar, K. Smita, L. Cumbal, A. Debut, Green synthesis of silver nanoparticles using Andean blackberry fruit extract, Saudi Jour. Biol. Sci. 24 (2017) 45-50.

[2] R. Arunachalam, S. Dhanasingh, B. Kalimuthu, M. Uthirappan, Phytosynthesis of silver nanoparticles using Coccinia grandis leaf extract and its application in the photocatalytic degradation, Colloid. Surf. B: Biointerf. 94 (2012) 226-230.

[3] P. Galletto, P.F. Brevet, H.H. Girault, R. Antoine, M. Broyer, Enhancement of the second harmonic response by adsorbates on gold colloids: the effect of aggregation, J. Phys. Chem. B 103 (1999) 8706-8710.

[4] M. Daniel, D. Astruc, Gold nanoparticles : assembly, supramolecular chemistry, quantum-size-related properties, and applications toward biology, catalysis, and nanotechnology, Chem. Rev. 104 (2004) 293-346.

[5] H. Tsunoyama, H. Sakurai, N. Ichikuni, Y. Negishi, T. Tsukuda, Colloidal gold nanoparticles as catalyst for carbon - carbon bond formation : application to aerobic homocoupling of phenylboronic acid in water, Langmuir 20 (2004) 11293-11296.

[6] C.M. Welch, R.G. Compton, The use of nanoparticles in electroanalysis : a review, Anal. Bioanal. Chem. 384 (2006) 601-619.

[7] S. Sun, C.B. Murray, D. Weller, L. Folks, A. Moser, Monodisperse FePt nanoparticles and ferromagnetic FePt nanocrystal superlattices, Sci. 287 (2000) 2-6.

[8] B.S.A. Maier, M.L. Brongersma, P.G. Kik, S. Meltzer, A.A.G. Requicha, H.A. Atwater, Plasmonics DA route to nanoscale optical devices, Adv. Mater. 13 (2001) 1501-1505

[9] M. Han, X. Gao, J.Z. Su, S. Nie, Quantum-dot-tagged microbeads for multiplexed optical coding of biomolecules, Nat. Biotechnol. 19 (2001) 631-635.

[10] J.L. West, N.J. Halas, Engineered nanomaterials for biophotonics applications : improving, Rev. Biomed. Eng. 5 (2003) 285-292.

[11] N. Leopold, B. Lendl, A new method for fast preparation of highly surfaceenhanced raman scattering (SERS) active silver colloids at room temperature by reduction of silver nitrate with hydroxylamine hydrochloride, J. Phys. Chem. B 107 (2003) 5723-5727.

[12] Y. Zhang, F. Chen, J. Zhuang, Y. Tang, D. Wang, Y. Wang, A. Dong, Synthesis of silver nanoparticles via electrochemical reduction on compact zeolite film modified electrodes, Chem. Commun. 23 (2002) 2814-2815.

[13] M. Darroudi, A. Khorsand, M.R. Muhamad, N.M. Huang, M. Hakimi, Green synthesis of colloidal silver nanoparticles by sonochemical method, Mater. Lett. 66 (2012) 117-120.

[14] T.K. Varadarajan, Thermal decomposition as route for silver nanoparticles, Nanoscale Res. Lett. (2007) 44-48.

[15] G.A. Kahrilas, L.M. Wally, S.J. Fredrick, M. Hiskey, A.L. Prieto, J.E. Owens, Microwave-assisted green synthesis of silver nanoparticles using orange peel extract, Chem. Eng. 2 (2014) 367-376.

[16] M.J. Rosemary, T. Pradeep, Solvothermal synthesis of silver nanoparticles from thiolates, J. Colloid Interf. Sci. 268 (2003) 81-84.

[17] M. Harada, Y. Kimura, K. Saijo, T. Ogawa, S. Isoda, Photochemical synthesis of silver particles in Tween 20 / water / ionic liquid microemulsions, J. Colloid Interf. Sci. 339 (2009) 373-381.

[18] X.Z. Lin, A.D. Terepka, H. Yang, Synthesis of silver nanoparticles in a continuous flow tubular microreactor, Nano Lett. 4 (2004) 1-6.

[19] A. Ahmad, P. Mukherjee, S. Senapati, D. Mandal, M.I. Khan, M. Sastry, Extracellular biosynthesis of silver nanoparticles using the fungus Fusarium oxysporum, Colloid. Surf. B 28 (2003) 313-318.

[20] B.I. Willner, R. Baron, Growing metal nanoparticles by enzymes, Adv. Mater. 18 (2006) 1109-1120

[21] J.L. Gardea-Torresdey, E. Gomez, J.R. Peralta-videa, J.G. Parsons, H. Troiani, M. Jose-yacaman, Alfalfa sprouts: A natural source for the synthesis of silver nanoparticles, Langmuir 19 (2003) 1357-1361.

[22] S.S. Shankar, A. Ahmad, M. Sastry, Geranium leaf assisted biosynthesis of silver nanoparticles, Biotechnol. Prog. 19 (2003) 1627-1631.

[23] S.S. Shankar, A. Rai, A. Ahmad, M. Sastry, Rapid synthesis of Au, Ag, and bimetallic Au core-Ag shell nanoparticles using Neem (Azadirachta indica) leaf broth, J. Colloid Interf. Sci. 275 (2004) 496-502.

[24] B. Ankamwar, C. Damle, A. Ahmad, M. Sastry, Biosynthesis of gold and silver nanoparticles using Emblica officinalis fruit extract, their phase transfer and transmetallation in an organic solution, J. Nanosci. Nanotechnol. 5 (2005) 1665-1671.

[25] S.P. Chandran, M. Chaudhary, R. Pasricha, A. Ahmad, M. Sastry, Synthesis of gold nanotriangles and silver nanoparticles using aloe vera plant extract, Biotechnol. Prog. 22 (2006) 577-583.

[26] J. Xie, J.Y. Lee, D.I.C. Wang, Y.P. Ting, Silver nanoplates: from biological to biomimetic synthesis, ACS Nano 1 (2007) 429-439.

[27] M.N. Nadagouda, R.S. Varma, Green synthesis of silver and palladium nanoparticles at room temperature using coffee and tea extract, Green Chem. 10 (2008) 859-862.

[28] A.R. Vilchis-nestor, V. Sánchez-Mendieta, M.A. Camacho-López, R.M. GómezEspinosa, M.A. Camacho-López, J.A. Arenas-Alatorre, Solventless synthesis and optical properties of $\mathrm{Au}$ and $\mathrm{Ag}$ nanoparticles using Camellia sinensis extract, Mater. Lett. 62 (2008) 3103-3105.

[29] T.C. Prathna, N. Chandrasekaran, A.M. Raichur, A. Mukherjee, Physicochemical and engineering aspects kinetic evolution studies of silver nanoparticles in a bio-based green synthesis process, Colloids Surf. A. 377 (2011) 212-216.

[30] T.Y. Suman, S.R.R. Rajasree, A. Kanchana, S.B. Elizabeth, Characterization and cytotoxic effect of plant mediated silver nanoparticles using Morinda citrifolia root extract, Colloids Surf. Biointerf. 106 (2013) 74-78.

[31] N.C. Nair, H.A. Henry, Flora of Tamil Nadu, Botany Survey of India, India, 1983

[32] Z. Yan, L. Fu, X. Zuo, H. Yang, Green assembly of stable and uniform silver nanoparticles on 2D silica nanosheets for catalytic reduction of 4-nitrophenol, Appl. Catal. B 226 (2018) 23-30. 
[33] T. Varadavenkatesan, R. Selvaraj, R. Vinayagam, Phyto-synthesis of silver nanoparticles from Mussaenda erythrophylla leaf extract and their application in catalytic degradation of methyl orange dye, J. Mol. Liq. 221 (2016) 10631070.

[34] P. Logeswari, S. Silambarasan, J. Abraham, Synthesis of silver nanoparticles using plants extract and analysis of their antimicrobial property, Jour. Saudi Chem. Soc. 19 (2015) 311-317.

[35] J.K. Patra, K. Baek, Green synthesis of silver chloride nanoparticles using Prunus persica L . outer peel extract and investigation of antibacterial, anticandidal, antioxidant potential, Green Chem. Lett. Rev. 9 (2016) 132-142.

[36] G.D. Wright, Resisting resistance: New chemical strategies for battling superbugs, Chem. Biology. 7 (2000) 127-132.

[37] K. Ramar, V. Vasanthakumar, A. Priyadharsan, P. Priya, V. Raj, P.M. Anbarasan, et al., Green synthetic approach of silver nanoparticles from Bauhinia tomentosa Linn. leaves extract for potent photocatalytic and in vitro biological applications, J. Mater. Sci. Mater. Electron. 29 (2018)11509-11520.

[38] A.J. Ahamed, K. Ramar, P.V. Kumar, Chemical synthesis of CdSe nanoparticles by using hydrazine monohydrate as a reducing agent, J. Environ. Nanotechnol. 5 (2016) 29-33.
[39] A.J. Ahamed, K. Ramar, P.V. Kumar, Synthesis and characterization of ZnSe nanoparticles by co-precipitation method, J. Nanosci. Technol. 2 (2016) 148150.

[40] D. Mukundan, R. Mohankumar, R. Vasanthakumari, Green synthesis of silver nanoparticles using leaves extract of Bauhinia tomentosa linn and its invitro anticancer potential, Mater. Today Proc. 2 (2015) 4309-4316.

[41] M.M.H. Khalil, Green synthesis of silver nanoparticles using olive leaf extract and its antibacterial activity, Arab. Jour. Chem. 7 (2014) 1131-1139.

[42] K. Jyoti, A. Singh, Green synthesis of nanostructured silver particles and their catalytic application in dye degradation, Jour. Gen. Eng. Biotechnol. 14 (2016) 311-317.

[43] V. Thivaharan, S. Raja, V. Ramesh, Phyto-synthesis of silver nanoparticles from Mussaenda erythrophylla leaf extract and their application in catalytic degradation of methyl orange dye, J. Mol. Liq. 221 (2016) 1063-1070.

[44] L. Cui, P. Chen, S. Chen, Z. Yuan, C. Yu, B. Ren, K. Zhang, In situ study of the antibacterial activity and mechanism of action of silver nanoparticles by surface-enhanced raman spectroscopy, Anal. Chem. 85 (2013) 5436-5443. 